\title{
La luna de los misioneros de Asia oriental a cuatro siglos de Diego de Pantoja
}

\author{
Manel Ollé \\ Universitat Pompeu Fabra
}

\section{Resumen}

El objetivo de abarcar China en la primera época moderna puede ser comparado con la meta espacial de la llegada a la luna: así lo describió un misionero franciscano en la década de 1570 . Se trataba de una misión larga, costosa y peligrosa. Una vez establecidos los primeros contactos permanentes se inició un camino lento y difícil en el que los misioneros dominicos, franciscanos o jesuitas trataron de abordar diversas estrategias que revelan puntos de contacto entre ellas y de apoyo mutuo. En este texto, fruto de la intervención en el encuentro, presentamos esas estrategias, con una mención específica al padre jesuita Diego de Pantoja, de quien en 2018 se conmemora el cuatrocientos aniversario de su muerte.

Palabras clave: China, misioneros, contacto cultural, acomodación cultural, Diego de Pantoja.

\section{La lluna dels missioners d'Àsia Oriental a quatre segles de Diego de Pantoja}

\section{Resum}

L'objectiu d'abastar la Xina en la primera època moderna pot ser comparat amb la meta espacial de l'arribada a la Lluna: així ho va descriure un missioner franciscà en la dècada de 1570 . Es tractava d'una missió llarga, costosa i perillosa. Un cop establerts els primers contactes permanents es va iniciar un 
camí lent i difícil en què els missioners dominics, franciscans o jesuïtes van tractar d'abordar diverses estratègies que revelen punts de contacte entre elles i de suport mutu. En aquest text, fruit de la intervenció al workshop, presentarem aquestes estratègies, amb una menció específica al pare jesuïta Diego de Pantoja, de la mort del qual es commemora el 2018 el quatre-cents aniversari.

Paraules clau: Xina, missioners, contacte cultural, acomodació cultural, Diego de Pantoja.

\section{The moon of the East Asian missionaries four centuries after Diego de Pantoja}

\section{Abstract}

The goal of embracing China in the early modern era could be compared to the spatial goal of travelling to the moon: it was described thus by a Franciscan missionary in the I570s. This was a long, expensive, and dangerous mission. Once the first permanent contact was established, a slow and difficult journey began in which Dominican, Franciscan and Jesuit missionaries tried different strategies to find points of contact between them and mutual support. In this text, a result of participation in the workshop, we present these strategies, with specific reference to Jesuit Father Diego de Pantoja, as we commemorate the 40oth anniversary of his death in 2018 .

Keywords: China, missionaries, cultural encounter, cultural accommodation, Diego de Pantoja.

El fraile franciscano Pedro de Alfaro escribió en Manila, a finales de la década de I570, que «intentar entrar en China, con o sin soldados, es como querer alcanzar la luna». En esta imagen se refleja tanto la dificultad como la fascinación que ejercía China para los misioneros europeos de finales del quinientos. Aunque la metáfora lunar del padre Alfaro pueda parecer más poética que ajustada a los hechos, ciertamente lo más semejante en nuestro tiempo a las aventuras de exploración, conquista, comercio y predicación religiosa en tierras tan lejanas y desconocidas como las de Asia oriental que emprendieron los europeos de 
finales del quinientos es la imagen de la épica de la exploración espacial que arreció desde mediados del siglo xx. En ambos casos implica un costoso viaje a lo desconocido, lleno de peligros e incertidumbres. Nada más parecido hoy a una incursión espacial que los largos meses de navegación incierta por mares y océanos ignotos, con cartografías tentativas, tifones, naufragios, abordajes de corsarios, escorbuto, aguas infectas y fiebres tropicales de imposible curación. No olvidemos que en la travesía del océano Pacífico el promedio de mortalidad se acercaba al $50 \%$ de los embarcados en cada galeón.

Y una vez superados los escollos del trayecto, aparece el contacto y la interacción, el trato y la predicación entre extraños seres de lejanas galaxias culturales: seres de sociedades asiáticas fundadas en códigos culturales por completo ajenos al marco propio. Los misioneros de la era moderna encontraban en Asia oriental sociedades sólidas, tan o más complejas, sofisticadas y desarrolladas que las europeas, muy organizadas, tan desconocidas como herméticas, nada fáciles de tratar y menos de convertir o de someter.

En el proceso de expansión imperial que emprendieron portugueses y castellanos durante el siglo xvi, el encuentro con Japón y, sobre todo con China, los enfrentó al reto inesperado de vérselas con civilizaciones letradas, de moralidad reglada y, en muchos aspectos, por aquel entonces, más prósperas, tecnológicamente avanzadas, complejas y ordenadas que la Europa de las guerras endémicas de territorio y de religión, las pestes y las epidemias, y las confrontaciones entre señores, jerarcas religiosos y monarcas en el proceso en marcha de construcción del Estado moderno.

El encuentro entre los europeos y los chinos en la era moderna resultó ser, además, el difícil diálogo entre dos etnocentrismos: dos mundos por completo desconectados que vivían instalados con comodidad en la suposición de ser netamente superiores a sus vecinos y de estar situados justo en el centro del mundo. El eurocentrismo y el sinocentrismo compartían, así, el espejismo de una centralidad que este encuentro contribuía a cuestionar con timidez. Cada etnocentrismo se formulaba en términos distintos: mientras el eurocentrismo era del 
todo expansivo, dominador y cristianizador, el sinocentrismo era defensivo, jerarquizador y separador.

El jesuita José Acosta clasificó en su obra De procuranda Indiorum Salute los distintos tipos de «indios» según su grado de desarrollo humano, cultural y civilizatorio. En el caso de japoneses y chinos, habló de «indios gentiles», tan paganos y cultos como los gentiles del pasado clásico, es decir, los griegos y los romanos.

Estos «indios gentiles» de Japón y de China, tan alejados de los indios tribales de las Américas y las islas y los estrechos de los mares del sur, exigían un esfuerzo sin precedentes. La predicación en estos nuevos imperios descubiertos por los europeos planteaba de entrada algunas preguntas de incómoda respuesta: ¡cómo era posible que al margen de la tradición cristiana y de la inteligencia europea se hubiese desarrollado una civilización tan antigua, culta y refinada como aquella que florecía en Asia oriental? Proliferaron las respuestas difusionistas (como las de Athanasius Kircher), que apuntaban a que en realidad la civilización china (y sus raras letras) procedían de Egipto o de Súmer, o mejor aún, de una tribu judía extraviada. Otros afirmaron que la predicación del apóstol santo Tomas o del preste Juan llegó a aquellas tierras asiáticas, y que la huella de un cristianismo primigenio del que ya se habían olvidado era aún rastreable en algunas figuras de devoción femenina china asimiladas a la Virgen María (como la bodhissatva Guanyin o la diosa marinera de Fujian, Mazu), y en la moralidad y buen tino de una parte nada desdeñable de la tradición confuciana.

Ya en el plano estrictamente misional, este nuevo encuentro en Asia oriental planteaba otra pregunta capital: ¿cómo podría conseguirse que los chinos abandonasen sus costumbres, sus creencias y sus rituales, su cosmovisión y su sentimiento de centralidad y de superioridad cultural para adoptar la religión católica? Las distintas órdenes religiosas y los diferentes misioneros destacados en China formularon respuestas implícitas o explícitas a esta cuestión. Franciscanos, dominicos o jesuitas desplegaron estrategias, que aunque en principio parecían enfrentadas, su estudio atento permite revelar ciertos puntos de contacto, e incluso 
momentos de cooperación o de relativa admiración mutua. Así, por ejemplo, a pesar del Odium Theologicum predominante en las relaciones entre los jesuitas y el resto de órdenes (sobre todo franciscanos y dominicos) que intentaban disputar el monopolio misional de la Compañía de Jesús en China o Japón, el dominico Juan Cobo nos informa, gozoso, en su carta de julio de 1589 , que tenía en su posesión un ejemplar del catecismo del padre de la Compañía de Jesús Michele Ruggieri, y que se servía de él para aprender los caracteres chinos, tras haberlo pasado «letra por letra».

Juan Cobo (no sin antes haber lanzado algunos dardos envenenados contra los misioneros jesuitas de China debido a su estrategia de dirigirse a las elites poderosas y no a la población llana) elogia en su carta, sin ningún tipo de reparo, la capacidad del 天主實錄 (Tianzhu Shilu) del jesuita Michele Ruggieri para desmentir errores y disparates en las creencias de los chinos:

Tambien el Padre de la Compañia que está en China ha escrito, y está impreso en letras chinas un libro todo él, de la Unidad de Dios, y de la Creacion del mundo, y de los Mandamientos, explicados; y llega hasta la Encarnacion del Hijo de Dios en este libro. De este (libro) no hablo de oídas, porque yo le tengo, y estoy tan cierto de ello, como quien lo ha pasado letra por letra, que así lo he pasado todo. Del cual me he aprovechado para las letras Chinas, que despues diré de ellas. Este libro esta impreso en China, año de mil y quinientos y ochenta y cuatro. Anda publicamente en China, y de alla le hubimos nosotros; y con escribir en él contra algunos disparates que tienen los Chinos, no le han hecho mal ninguno: de donde se infiriere, que no es $\tan$ bravo el leon como lo pintan. Esto es de lo que toca la tierra firme de China, que nosotros no habemos visto. ${ }^{1}$

Aunque en buena medida fracasaron en su intento de conseguir unas cifras relevantes de conversiones al catolicismo, es plausible afir-

I. Antonio de Remesal, Historia de la Provincia de San Vicente de Chiapa y Guatemala de la Orden de Nto. Glorioso Padre Santo Domingo, Impreso por Francisco de Angulo, Madrid, I6r9, libro XI, ff. 679-687. 
mar que las respuestas más audaces a esta cuestión las supieron dar en Japón y en China los padres jesuitas con una estrategia que tenía varias facetas. Primero, estaba el ya aludido acercamiento preferente a las elites y a los máximos mandatarios para conseguir conversiones influyentes de repercusión en cadena. Tenía un lugar destacado, asimismo, la modulación y adaptación relativa de la predicación, la apologética y la acción misional a los discursos dominantes en estas sociedades a convertir: a su tradición, sus concepciones del mundo y sus creencias, sus sistemas filosóficos, sus usos y costumbres, sus formas de vida, sus vestimentas y códigos sociales, sus ritos y jerarquías. Y también hay que mencionar la estrategia de ofrecer no solo un discurso de predicación religiosa, sino también exhibir y compartir regalos valiosos, objetos tecnológicamente complejos, conocimientos científicos y humanísticos (astronomía, geografía, matemáticas, música...), que permitiesen a estas elites cultas chinas reconocer la valía y superioridad de estos misioneros europeos.

Para hacerse un lugar en la conversación culta de su tiempo en China, los jesuitas de China optaron por aprender la lengua de los letrados. Estudiaron sus clásicos y sus conocimientos, adoptaron una versión propia de sus vestimentas y sus tocados y trazaron puentes retóricos, conceptuales y referenciales, que ayudasen a hacer comprensible y aceptable el cristianismo.

En este esfuerzo de aproximación cultural vemos el umbral de la llamada estrategia de adaptación misional, que aboga ya en el plano religioso por buscar formas de síntesis que permitan el mantenimiento de parte del ritualismo y del sistema de creencias y valores morales, del estilo discursivo y de referentes propios del ámbito a cristianizar. Esta estrategia empezó a forjarse en Japón ya en tiempos de Francisco Xavier, y maduró plenamente con Alessandro Valigano, que decidió exportarla a China. El confucianismo y el culto a los antepasados, así como el ritualismo imperial al Cielo y la Tierra, entre otras cosas, forman parte de este complejo de ritos y creencias con los que se intentaba contemporizar, presentándolos como compatibles con el catolicismo en la medida en que no parecían contradecir el núcleo del dogma cris- 
tiano. En este esfuerzo, el papel de Diego de Pantoja es de la máxima importancia. Y no solo como adlátere de Mateo Ricci.

Liderados por Mateo Ricci, los padres jesuitas fueron los primeros en tocar de cerca este objeto del deseo misional. En la culminación del tránsito hasta el corazón mismo del Imperio, en los pabellones imperiales de la Ciudad Prohibida de Beijing, ya a inicios de siglo xvir, cobra una importancia singular la figura del padre jesuita castellano Diego de Pantoja (I57I-I6I8), de cuyo deceso se celebra en 2018 el cuatrocientos aniversario, una importancia a la que no se le ha dedicado la atención suficiente, en parte por el brillo cegador del líder de la misión, Mateo Ricci, que ensombrece a sus compañeros y colaboradores. Y también porque la ausencia de una tradición sinológica fuerte y de una historiografía misional actualizada en el ámbito hispánico ha hecho que su figura esté desatendida de manera incomprensible, o muy poco explicada. Y al haber escrito en chino y en español, Diego de Pantoja ha quedado también prácticamente fuera del ámbito de la academia anglosajona.

El hecho de que Pantoja fuera castellano influyó, asimismo, en su invisibilidad, incluso cuando entró en China. La empresa misional católica estaba en gran medida ligada al proceso de expansión imperial ibérica, que según los momentos y los lugares tenía acentos más comerciales, más diplomáticos o más puramente bélicos. La llegada de los jesuitas a China se produjo en tiempos de la unión dinástica entre Castilla y Portugal, en una monarquía compuesta, que reunía distintos reinos bajo la misma corona.

La misión jesuita en Asia se expandió desde Goa bajo el manto del Patronato Real portugués. Las ambiciones castellanas sobre China llevaron a los superiores jesuitas a intentar desvincular a la misión jesuita de estas disputas nacionales luso-castellanas, otorgando un gran protagonismo a la neutralidad de los padres italianos: Ricci, Ruggireri, Passio, Cattaneo, Longhobardi, etc.

Por otro lado, la fama de poder amenazante y deseoso de nuevas conquistas en China que se habían ganado los castellanos de Manila (en parte por mérito propio, y sobre todo como fruto de la maledicencia de los portugueses de Macao) hizo que las autoridades jesuitas evi- 
taran la presencia de misioneros castellanos en China. De hecho, Diego de Pantoja fue una excepción: el primer misionero castellano en China, impuesto contra el criterio de los misioneros que estaban sobre el terreno para acallar rumores sobre la exclusión de los castellanos. Probablemente, su procedencia castellana no es ajena a la prevención con la que en algunos escritos lo presenta Ricci, o incluso a cierta invisibilidad de su figura.

Tal vez los ecos en Beijing de la matanza masiva de alrededor de 20.000 mercaderes estacionales y emigrantes chinos que llevaron a cabo las autoridades castellanas de Manila como respuesta a una rebelión china en $\mathrm{I} 603$ no sea ajena a algunas tensiones e incomodidades que pudo generar la figura de Diego de Pantoja. El peligro de ser asociados con aquellos castellanos de Manila era grande. Mateo Ricci cuenta los diversos esfuerzos para evitar ser confundidos con los españoles de Manila en las cartas que envió en aquellos años.

Superando toda esta fatal conjura de olvidos, por último, en el marco de la investigación china, se ha empezado a hacer justicia con la figura de Diego de Pantoja, gracias a la acción pionera del profesor Zhang Kai, que ha tenido un efecto germinal que ha sabido fructificar en nuevas aproximaciones, estudios y ediciones como el que ahora nos ocupa.

La figura de Diego de Pantoja no destaca tanto por haber dado salida a su fascinación por China como por haber superado retos de una dificultad sin precedentes en una posición pionera. La faceta de la obra de Diego de Pantoja que se ha conocido mejor hasta ahora fuera del ámbito chino ha sido su contribución a la difusión de noticias y percepciones del Imperio Celeste, que satisficieron la enorme curiosidad que tenían las elites cultas europeas acerca de China y la incursión jesuita en curso. La aportación de Diego de Pantoja actualizó, matizó y completó las descripciones de China que habían ido poniendo en circulación portugueses y castellanos desde mediados del siglo Xvi, y que habían quedado sintetizadas en la obra del agustino Juan González de Mendoza Historia del Gran Reino de la China, publicada en 1585 , con más de cuarenta ediciones distintas y con traducciones a diferentes lenguas europeas. 
Diego de Pantoja consiguió también una amplia repercusión con la obra de 1603 Relación de la entrada de algunos padres de la compañía de Jesús en la China y particulares sucesos que tuvieron y de cosas muy notables que vieron en el mismo reino. Carta del padre Diego de Pantoja, religioso de la Compañía de Jesús, para el padre Luis de Guzmán, provincial de la provincia de Toledo, de la que se realizaron hasta ocho ediciones en cinco lenguas europeas diferentes. En ella describió la entrada de los jesuitas en China, así como diversos aspectos de la historia, la geografía o la cultura china. En esta carta-relación de 265 páginas, entre otras novedades, Diego de Pantoja ofrece la primera descripción detallada de la Ciudad Prohibida, al contarse entre los primeros europeos que tuvieron el raro privilegio de cruzar repetidamente su umbral.

A pesar de su importancia en el proceso de construcción de la imagen de China en la Europa de inicios del siglo xvir, y del impacto intelectual que llegó a tener esta carta-relación de I603, escrita a los pocos años de entrar en China, en realidad no encontramos en ella la principal aportación de Diego de Pantoja al intercambio cultural entre China y Europa. Es sobre todo en su obra teológica y de divulgación del catolicismo, redactada en chino, pero también en algunos episodios de su recorrido biográfico de la acción misional y de la interacción cultural y personal en el Palacio Imperial y en círculos relevantes de letrados chinos, donde podemos empezar a vislumbrar la singularidad y la grandeza de su figura.

Casi de forma coetánea a la difusión de la obra de Ricci escrita en chino, Diego de Pantoja escribe una serie de tratados en esa lengua y colabora con otros padres en la traducción de obras astronómicas. También en esto es un pionero, un avanzado a su tiempo. Durante el siglo siguiente, otros misioneros alcanzarán, como ellos, un dominio suficiente del chino clásico como para poder redactar obras teológicas, científicas o humanísticas destinadas a las elites cultas.

En su periplo biográfico misional destacan sus más y sus menos con los eunucos que rodeaban al más ausente de los emperadores, Wanli, retirado de los quehaceres mundanos y renuente a recibir visita alguna, o su habilidad con el clavecín, los relojes o la reforma del calendario, 
que le lleva de forma precursora y sin precedentes a frecuentar el Palacio Imperial y los círculos cercanos al emperador. Destaca, asimismo, su habilidad diplomática al conseguir el beneplácito imperial para la obtención de un terreno para construir la tumba de Mateo Ricci (en un movimiento de muy alta significación, ya que de facto legitima la presencia misional jesuita en el interior de China).

El estudio de la obra china de Diego de Pantoja abre nuevas perspectivas de avance y de clarificación sobre su aportación y su incalculable valor. Su obra fue leída, prologada y comentada por importantes letrados de su tiempo. Ponerla de nuevo en circulación puede servir para empezar a clarificar cuestiones muy relevantes, como, por ejemplo, saber con detalle hasta qué punto y de qué modo Pantoja reformuló las estrategias jesuitas de adaptación, en qué términos se produce su crítica al budismo y qué aspectos de las creencias y costumbres chinas rechaza con más ardor (como, por ejemplo, la poligamia), o de qué conceptos chinos se sirve para traducir o explicar sus argumentos religiosos y teológicos. Asimismo, puede permitir vislumbrar qué juego dieron sus aportaciones en el discurso filosófico chino coetáneo entre distintas tendencias de letrados.

Al escucharle desde la distancia de los siglos, sabemos que quizás fue derrotado, que murió en la expulsión y el exilio misional en Macao, que no alcanzó a llegar del todo a su anhelada luna china: a su ideal de conversión al cristianismo de emperadores, letrados, eunucos y gente común. Pero sabemos también que del trayecto de su aventura china han quedado registrados algunos de sus gestos y buena parte de sus palabras, que más allá de su primera intención persuasiva nos hablan de un diálogo entre culturas y entre lenguas, de una querencia, de una fascinación y de un esfuerzo por llegar al otro lejano: un esfuerzo titánico por hacerse entender en una lengua alejada, una cosmovisión, un estilo de pensamiento y en un código cultural también del todo extraño al propio. Las palabras que nos ha legado este proceso son dignas de estudio y de actualización. Y más que nunca en este mundo de hoy, que nos vuelve a acercar y nos quiere con una mente abierta y libre de orgullos y prejuicios estériles. 